\title{
Effect of Designed Guidelines for Mothers regarding Care of their Children with Ophthalmological Trauma
}

\author{
Doaa El-Maghawry Abd El-Halem ${ }^{1}$, Khadiga Mohamed Said ${ }^{2}$ and Hanan El-Sayed Metwally ${ }^{3}$ \\ (1) Nursing Specialist at Berket El-Saba Nursing Technical Secondary School, Egypt (2) Assistant \\ Professor of Pediatric Nursing, Faculty of Nursing, Benha University, Egypt and (3) Lecturer of \\ Pediatric Nursing, Faculty of Nursing, Benha University, Egypt
}

\begin{abstract}
Background: Ophthalmological trauma is a serious public health problem that may cause vision loss, mono-ocular visual disability and non-congenital mono-ocular blindness in children because of their immature motor skills and natural curiosity. Aim of study: Was to evaluate the effect of designed guidelines on mothers' knowledge and practice regarding care of their children with ophthalmological trauma. Design: A quasi- experimental design was utilized. Setting: The study was conducted at inpatient department at Specialized Ophthalmology Center affiliated to Benha University Hospital. Sample: A purposive sample of 80 mothers of children with ophthalmological trauma who attended the inpatient department of Specialized Ophthalmology Center. Tools of data collection: Three tools were used to conduct the study. I: Knowledge of mothers structured interviewing questionnaire. II: Medical and social characteristics of children and III: Care of ophthalmological trauma observational checklists which include eye care, application of hot and cold compresses, eye drops instillations, eye ointment application and eye irrigation. Results: There was a highly positive statistical correlation between mothers' total knowledge and their total practice scores at pre/ post-guidelines. Conclusion: The research hypothesis was accepted and the majority of studied mothers had adequate knowledge and satisfactory practice post implementation of designed guidelines as compared to pre designed guidelines with highly statistically significant improvement. Recommendations: The nursing roles should be directed toward educating mothers about proper care for children with ophthalmological trauma.
\end{abstract}

Key word: Children, Designed guidelines, Ophthalmological trauma.

\section{Introduction}

Children are vital to the nation's present and its future; they are exposed to a various epidemiological factors in the environment which affect their present and future state of health because they are characterized by curiosity, imitation and hyperactivity, especially small children. Also, they are not able to recognize the difference between dangerous and not dangerous objects (Guo et al., 2021).

Pediatric eye trauma refers to damage that result from direct physical injury to the eye, surrounding area, adjacent skin and bone structure. Eye injury leads to visual impairment which may have an association with children development. Children are already vulnerable in cognitive, motor, and social development, and their risk for delayed learning, limitations in skills acquisition, and impaired social relationships increases with this visual impairment. Children who are visually impaired have lower quality-of-life scores compared with their peers (Tichauer, 2021).

The nurse plays an important role for the prevention of pediatric ophthalmological 
trauma by increasing the awareness of the parents and family members about the common modes of trauma, the need for supervision of the objects of play. Selfprotection should be taught to children to prevent possible ocular injuries. She should ensure on environmental safety of houses, playgrounds and schools as regard common items of trauma such as sharp objects, household lime, and chemicals must be kept out of reach of children. The nurses also play an important role on mothers' education regarding pediatric eye trauma first aids (Hong \& Song, 2018).

\section{Significance of the study:}

Visual impairments as a result of ocular trauma lead to a variety of problems and still remain a significant cause of ocular morbidity. Pediatric ocular trauma forms about $20-50 \%$ of all eye injuries reported (Podbielski et al., 2016). Worldwide, as many as 6 million children annually sustain ocular trauma, with up to a quarter of a million children requiring hospitalization (Barry et al., 2019). Only few studies have been reported on ocular trauma in Egypt and especially pediatric groups. Since the 2011 the pattern and rate of ocular trauma have changed (Eldaly et al., 2013).

\section{Aim of the study:}

The aim of the study was to evaluate the effect of designed guidelines on mothers' knowledge and practice regarding care of their children with ophthalmological trauma.

\section{Research Hypothesis:}

Mothers who receive the designed guidelines would have higher level of knowledge and practices on posttest than pretest.

\section{Subject and methods:}

\section{Research design:}

A quasi- experimental design (pre and posttest) was utilized to conduct this study.

\section{Research setting:}

The current study was conducted at inpatient department at Specialized Ophthalmology Center affiliated to Benha University Hospital.

\section{Research sampling:}

A purposive sample of 80 mothers of children with ophthalmological trauma who attended the inpatient department of Specialized Ophthalmology Center during the period of data collection was included in the study.

\section{The inclusion criteria for children}

-from both sexes

-their ages from birth to 18 years old

-free from previous eye operations or problems

\section{Tools for data collection:}

Three tools were utilized for data collection:

\section{Tool I: Knowledge of mothers structured interviewing questionnaire sheet:}

It was developed by the researcher after reviewing recent literatures. It was written in an Arabic language. It contained the following.

- Part I: Personal data of the mothers such as: age, occupation, level of education, place of residence and social status.

- Part (2): Mothers' knowledge regarding ophthalmological trauma: Which included (17) items. 
Scoring system for mothers' knowledge assessment:

The complete correct answer scored (2). The incomplete correct answer scored (1). Don't know and incorrect answer scored (0). The total score for all 17 questions was 34 marks which represent $100 \%$. If the mothers' answers more than 20 score it considered adequate knowledge, if the mothers' answers less than 20 score it considered inadequate knowledge.

The total score of each mother was categorized into:

- Adequate knowledge: $(\geq 60 \%)$ of the total knowledge score.

- Inadequate knowledge: $(<60 \%)$ of the total knowledge score.

Tool II: Medical and social characteristics of children:

This tool consisted of two parts:

- Part (1): Personal characteristics of the children such as: age, gender, arranging the child among the family, education.

- Part (2): Medical data such as: medical diagnosis, previous ophthalmological trauma, signs and symptoms related to trauma, complication occurs after eye trauma.

Tool III: Care of Ophthalmological Trauma Observational Checklists:

It was adopted from Lippincott (2018) to assess mothers' care provided to their children with ophthalmological trauma. It includes eye care, application of hot and cold compresses; eye drops instillations, eye ointment application and eye irrigation. Score
(1) was given to a correct action. Score (0) was given to incorrect action or action not done. The total score for all 60 questions was 60 marks which represent $100 \%$. If the mother done 36 correct steps or more it considered satisfactory practice, if less than 36 correct steps it considered unsatisfactory practice.

The total scoring system of mothers' practice was categorized into:

- Satisfactory practice: $\geq 60 \%$.

- Unsatisfactory practice: $<60 \%$.

Tools validity:

Tools were submitted to a jury of three experts one Professor in Pediatric Nursing at Faculty of Nursing in Benha University and two assistant Professors in Pediatric Nursing. All required modifications were done.

\section{Tools reliability:}

Internal consistency of the tools was evaluated by using Cronbach's coefficiency alpha test. Reliability of knowledge equal 0.81 , reliability for practice equal 0.76 .

\section{Ethical considerations:}

A permission of the Dean of Faculty of Nursing at Benha University was obtained. Ethical Research Committee was obtained. Oral consent was taken from the mothers. Methods of data collection were explained to mothers. Each mother was assured of the confidentiality of her data and data of children.

\section{Pilot study:}

It was carried on a sample of $10 \%$ of the expected sample size ( 8 of mothers and their children) with ophthalmological trauma to evaluate the reliability and applicability of the tools and estimate the time required for answering the questionnaire. The tools were 
modified according to the results of the pilot study and experts' opinions.

\section{Field work:}

The process of data collection started from the beginning of September 2020 to the end of February 2021, covering a long period of 6 months, the researcher was available at study setting two days/week to collect data using the previous tool. The current study was carried out through the following phases:-

\section{a. Assessment phase}

The researcher interviewed each mother individually, introduced herself, greet mother, explained the aim of the study and take their approval to participate in the study prior data collection. The interview took about 25-35 minutes to fill the questionnaire sheet. The researcher assisted mothers who cannot fill the questionnaire, while their practice was assisted by using observational checklist during their actual practices. Each child with ophthalmological trauma was observed by the researcher and data was collected from the medical record (This takes nearly 5-10 minutes for each child), ensuring complete privacy and total confidentiality.

\section{b. Planning Phase}

After assessing their knowledge and practice, the researcher designed guidelines regarding knowledge and practice instructed for mothers. The guidelines designed by using simple Arabic language and different illustrated colored pictures in order to facilitate mothers understanding about ophthalmological trauma.

\section{c. Implementation phase}

The questionnaire sheets were administered to all mothers individually to assess their knowledge about ophthalmological trauma. The observational checklists were used to assess mothers' practice. After the pre-test, the researcher administered the designed guidelines to the mothers that based on mothers' knowledge and practices' needs. They were asked to feel free to ask any questions. The guidelines were given to the mothers to follow it as needed. Mothers were divided into groups, each group contains 3-5 mothers to acquire the related knowledge, and the researcher continued to reinforce the gained knowledge, answered any raised questions and gave feedback.

\section{Sessions of implementation:}

Sessions of implementation were achieved through four sessions, divided as follows: one session for knowledge and three sessions for practice. Each session started with a summary of the previous session and objectives of the new one. Taking into considerations the use of Arabic language that suits the mothers' educational level. Motivation and reinforcement during sessions were used in order to enhance motivation for participation in this study. The duration of skills sessions took 30-45 minutes and numbers of sessions were three sessions for each group (3-5 mothers) inform of demonstration and re-demonstration for each group. The researcher used group discussion, role playing, colored pictures and handouts as teaching methods for knowledge sessions.

Session 1: Program orientation and overview on ophthalmological trauma.

Session 2: Demonstration of practices (Eye care, hot and cold compresses).

Session 3: Demonstration of practices (Application of eye drops and eye ointments).

Session 4: Demonstration of practices (Eye irrigation). 


\section{d. Evaluation Phase:}

At the final session, the researcher asked the mother to answer post-test by using the same format of knowledge questionnaires sheet and perform observational checklists.

\section{Statistical analysis:}

The collected data was organized, coded, categorized, analyzed and tabulated using Statistical Package for Social Science (SPSS) version 20. Graphics were done using Excel program. Quantitative data was expressed as mean and standard deviation, while Qualitative data was expressed as percentage. Statistical test such as chi-square $\left(\mathrm{x}^{2}\right)$ was used for determining number and percentage distribution. Pearson correlation coefficient (r) was used for correlation analysis. A statistical significant difference was considered p-value $\mathrm{P}<0.05$. A highly statistical significant difference was considered if $\mathrm{p}$-value $\mathrm{P}<0.001$ and no statistical significant difference was considered if $\mathrm{p}$-value $\mathrm{P}>0.05$.

\section{Results}

Table (1): Illustrates that more than half $(61.2 \%)$ of the studied mothers were in age group $25<35$ years old with a mean age of $33.33 \pm 6.11$ years. Regarding mothers' education, less than half $(46.3 \%)$ of them had intermediate education. Also, slightly less than two thirds $(65.0 \%)$ of them were not working. As regards marital status, about two thirds $(66.3 \%)$ of studied mothers were married. Furthermore, Less than three quarters $(71.3 \%)$ of studied mothers lived in rural areas. Moreover, more than three quarters $(78.7 \%)$ of studied mothers had 3 - 5 family members.

Figure 1: Displays that $70.0 \%$ of mothers had adequate total knowledge score at post-guidelines compare to $31.3 \%$ of mothers had adequate total knowledge score at pre-guidelines.

Figure 2: Displays that $85.0 \%, 82.5 \%$ of mothers acquired their information about dealing with their children when eye injuries occur from parents and family and neighbors respectively, $71.25 \%$ of them acquired their information from doctor, $58.75 \%$ of them acquired their information from pharmacist, while $36.25 \%$ acquired their information from the net and only $26.25 \%$ of mothers acquired their information from the nurse.

Figure 3: Displays that $86.2 \%$ of the mothers had satisfactory total practice score at post-guidelines compare to $47.5 \%$ of the mothers had satisfactory total practice score at pre-guidelines.

Table (2): Shows that more than half $(53.7 \%)$ of the studied children were in age group $5<10$ years old with a mean age of $7.53 \pm 3.53$ years. Regarding child's gender, less than two thirds $(60.0 \%)$ of the studied children were male. More than half $(52.5 \%)$ of them were the second child in the family. As regards child's education, slightly less than half $(48.8 \%)$ of the studied children were in elementary stage.

Table (3): Clarifies that there is a highly positive statistical correlation between mothers' total knowledge and their total practice scores at pre/ post-guidelines $(\mathrm{p}<0.001)$. 
Table (1): Distribution of the studied mothers according to their personal data $(n=80)$.

\begin{tabular}{|c|c|c|}
\hline Personal characteristics & No. & $\%$ \\
\hline \multicolumn{3}{|l|}{ Mother's age/ year } \\
\hline $18<25$ & 9 & 11.3 \\
\hline $25<35$ & 49 & 61.2 \\
\hline$\geq 35$ & 22 & 27.5 \\
\hline \multicolumn{3}{|c|}{ Mean $\pm \mathrm{SD}=33.33 \pm 6.11$} \\
\hline \multicolumn{3}{|c|}{ The mother's education degree } \\
\hline Illiteracy & 2 & 2.5 \\
\hline Read and write & 7 & 8.7 \\
\hline Basic education & 14 & 17.5 \\
\hline Intermediate education & 37 & 46.3 \\
\hline University education & 20 & 25.0 \\
\hline \multicolumn{3}{|l|}{ The Mother's Job } \\
\hline Working & 28 & 35.0 \\
\hline Not working & 52 & 65.0 \\
\hline \multicolumn{3}{|l|}{ Marital Status } \\
\hline Married & 53 & 66.3 \\
\hline Divorced & 23 & 28.7 \\
\hline Widow & 4 & 5.0 \\
\hline \multicolumn{3}{|l|}{ Residence } \\
\hline Rural & 57 & 71.3 \\
\hline Urban & 23 & 28.7 \\
\hline \multicolumn{3}{|c|}{ Number of family members } \\
\hline 3 - 5 persons & 63 & 78.7 \\
\hline $6-8$ persons & 17 & 21.3 \\
\hline 9 persons or more & 0 & 0.0 \\
\hline
\end{tabular}




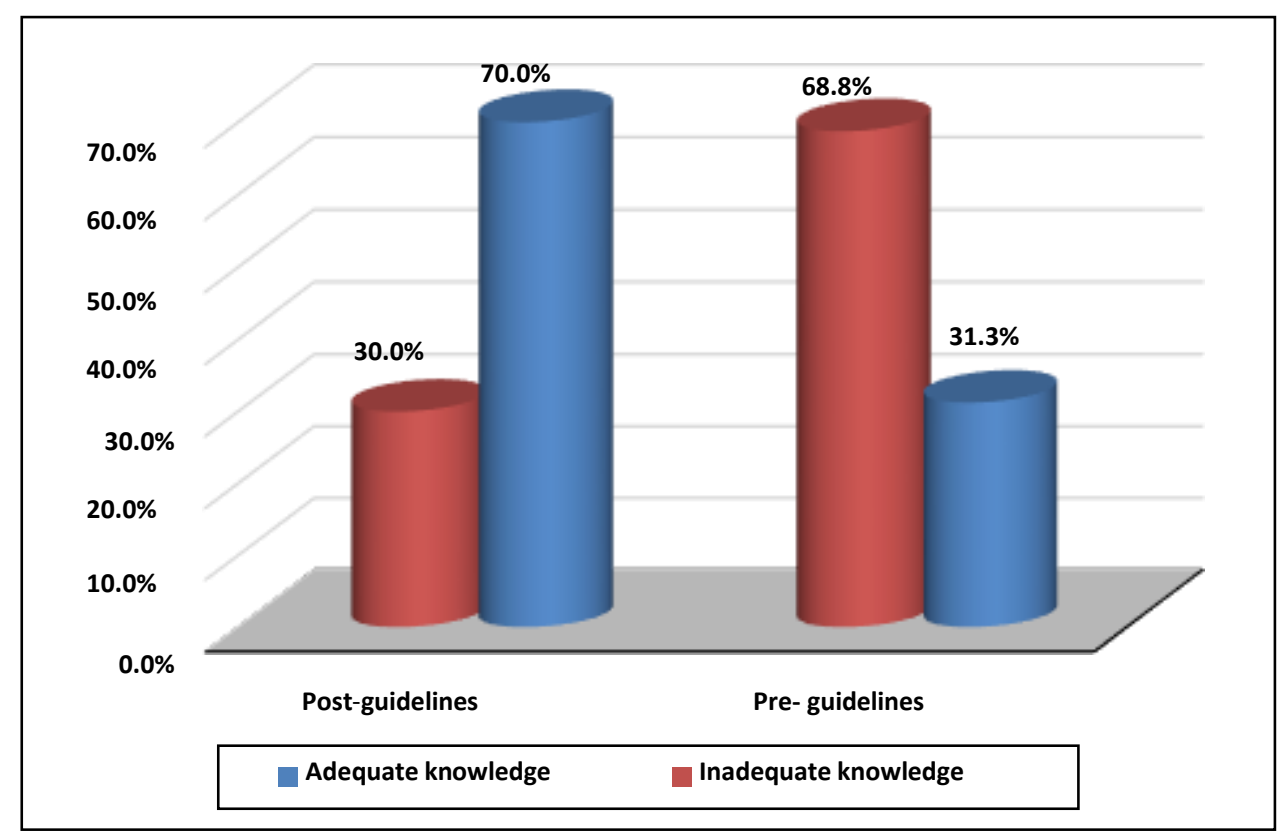

Figure (1): Distribution of studied mothers' total knowledge regarding ophthalmological trauma at pre/ post guidelines $(n=80)$.

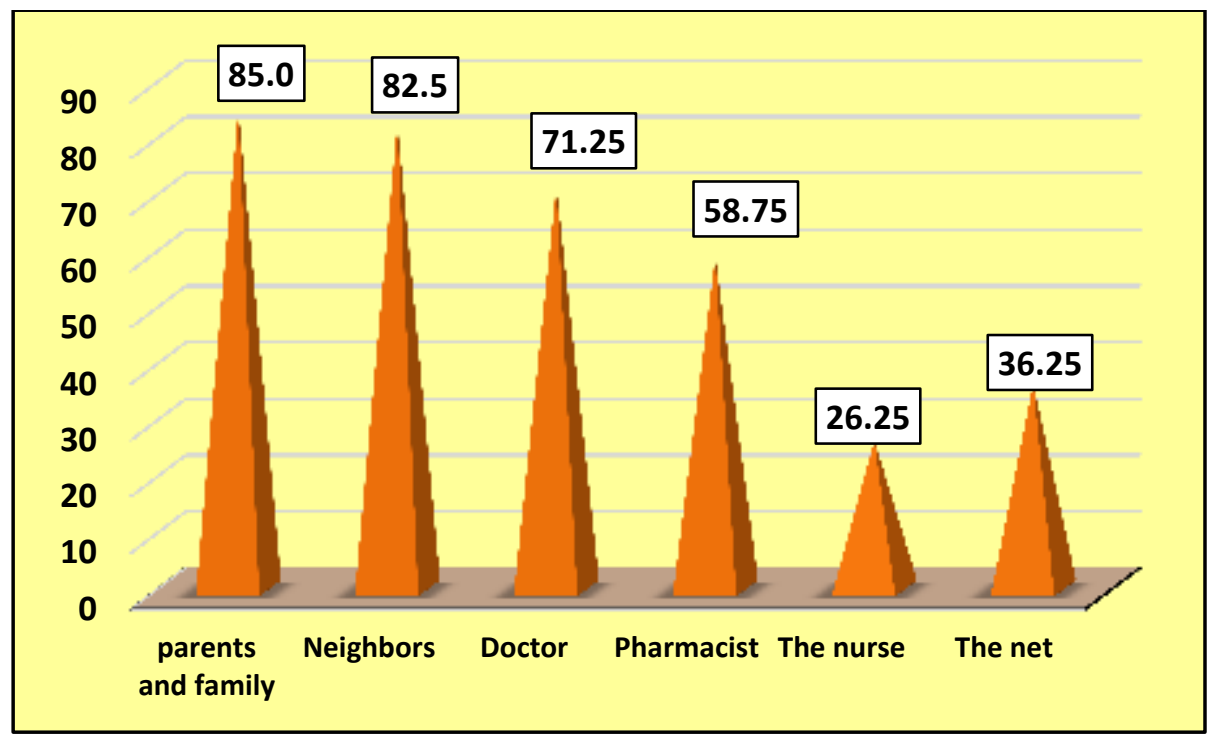

Figure (2): Percentage distribution of mothers' source of information about how to deal with their children when eye injuries occur $(n=80)$ 


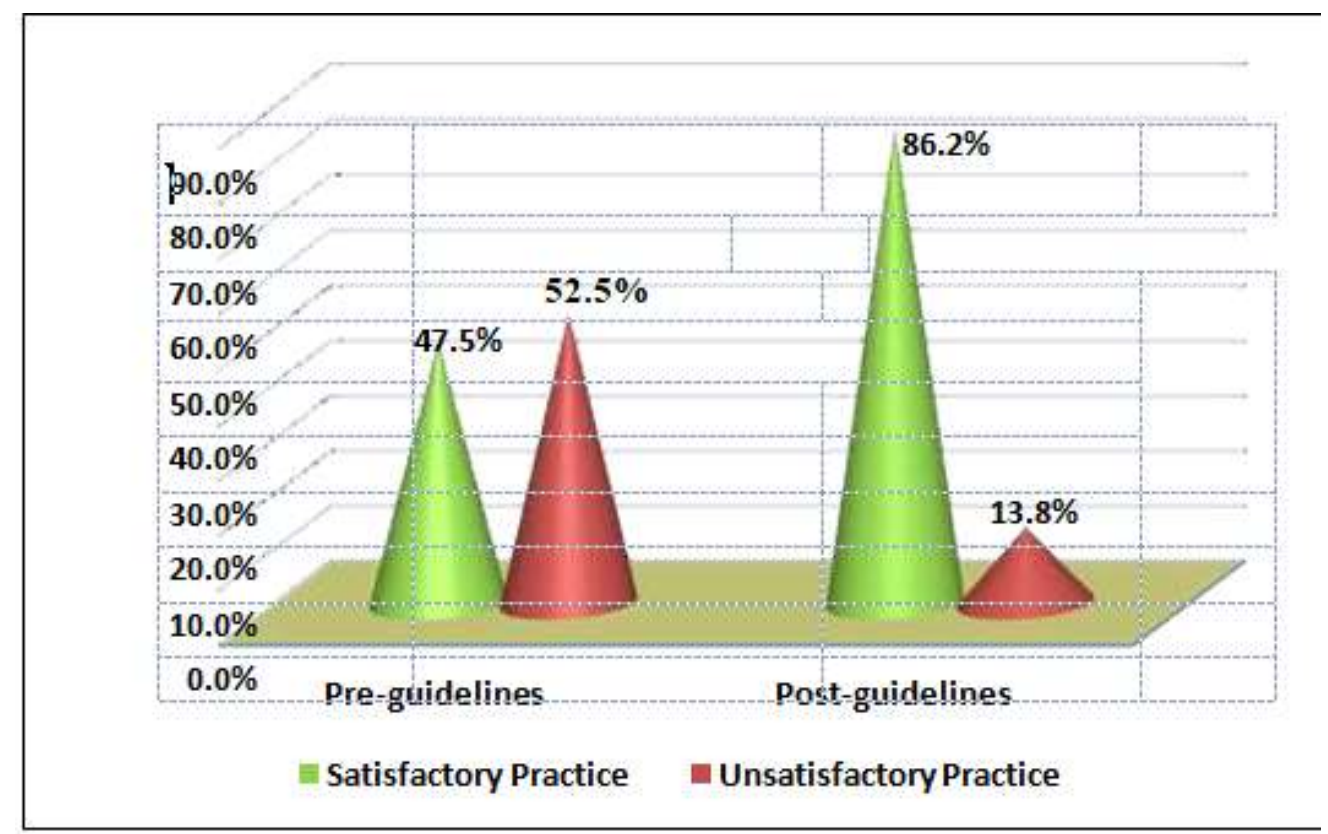

Figure (3): Percentage distribution of studied mothers' total practice scores at pre/ postguidelines $(\mathbf{n}=\mathbf{8 0})$.

Table (2): Distribution of Personal characteristics of studied children $(n=80)$.

\begin{tabular}{|c|c|c|}
\hline Personal characteristics & No. & $\%$ \\
\hline \multicolumn{3}{|l|}{ Child's age/ year } \\
\hline Less than a year & 0 & 0.0 \\
\hline $1<5$ & 23 & 28.8 \\
\hline $5<10$ & 43 & 53.7 \\
\hline $10-18$ & 14 & 17.5 \\
\hline \multicolumn{3}{|c|}{ Mean \pm SD $=7.53 \pm 3.53$} \\
\hline \multicolumn{3}{|l|}{ Child's gender } \\
\hline Male & 48 & 60.0 \\
\hline Female & 32 & 40.0 \\
\hline \multicolumn{3}{|c|}{ Arranging the child among the family } \\
\hline First & 8 & 10.0 \\
\hline Second & 42 & 52.5 \\
\hline Third & 23 & 28.8 \\
\hline Fourth & 7 & 8.7 \\
\hline \multicolumn{3}{|c|}{ The child's education degree } \\
\hline Pre-nursery & 0 & 0.0 \\
\hline Nursery & 28 & 35.0 \\
\hline Elementary stage & 39 & 48.8 \\
\hline Preparatory stage & 9 & 11.2 \\
\hline Secondary & 4 & 5.0 \\
\hline
\end{tabular}


Table (3): Correlation coefficient between studied mothers' total knowledge and total practices scores $(\mathbf{n}=\mathbf{8 0})$

\begin{tabular}{|c|c|c|c|c|}
\hline \multirow{3}{*}{ Variables } & \multicolumn{4}{|c|}{ Total knowledge } \\
\hline & \multicolumn{2}{|c|}{ Pre } & \multicolumn{2}{|c|}{ Post } \\
\hline & $\mathbf{r}$ & P-value & $\mathbf{R}$ & P-value \\
\hline Total practices & 0.70 & $.000 * *$ & 0.61 & $.000 * *$ \\
\hline
\end{tabular}

\section{Discussion}

Ophthalmological trauma is a major cause of non-congenital visual impairment and one of the most common causes of acquired blindness in children, because of their immature motor skills, limited common sense, tendency to imitate adult behavior without evaluating risks, lessened emotional control, relative ignorance, and natural curiosity. Although most eye trauma are avoidable by simple prevention measures, many children suffer from visual impairment that can seriously obstruct their psychosocial development. They face a lifetime of limited vision or even blindness, with all the associated emotional, social, and economic cost to the child, family, and society (D'Antone et al., 2021).

Concerning mothers' total knowledge about ophthalmological trauma, the current study reported that less than three quarters of mothers had adequate knowledge postguidelines compared to less than one third of mothers had adequate knowledge preguidelines. This finding had an agreement with Al Mazrou et al., (2020) who conducted a study about "Do Saudi parents have sufficient awareness of pediatric eye diseases in Riyadh?" and found that there is a lack of awareness among parents about common pediatric eye diseases and proper eye care behaviors. Therefore, awareness programs should be targeting both parents with a focus on mothers.

This finding also was in the same line with the study done by Carlsson et al., (2016) who conducted a study entitled " Mothers' awareness towards child injuries and injury prevention at home: an guidelines study" and found that the guidelines had a positive effect on mothers' awareness towards child injuries.

Regarding to the mothers' source of information about dealing with their children when eye injuries occur, the current study reported that the majority of mothers gained their information from parents and family and neighbors. This result consistent with the result of a study done by Al Mazrou et al., (2020) who found that the majority reported sources of information were community members (e.g., family members, relatives, friends, school, university, or workplace). In contrast, this finding disagreed with Baashar et al., (2020) who found that majority of parents gained their information from the family doctor. Also, this finding was incongruent with Sukati et al., (2018) who found that the majority of parents had information about eye diseases from doctors. The researcher interpreted that, as variations between mothers' concepts and cultures which returned to different environments and lifestyles. 
Concerning mothers' total practices about ophthalmological trauma pre and postguidelines, the current study shows that, highly statistically significant difference postguidelines compared to pre-guidelines regarding: Technique of eye care, application of hot compresses for affected eyes, application of cold compresses for affected eyes, technique of eye drops instillation and technique of eye irrigation. Meanwhile, there was a statistically significant difference postguidelines compared to pre-guidelines regarding technique of eye ointment application. This finding may be from the researcher point of view due to the positive effect of the designed guidelines in improving the level of mothers' practices about ophthalmological eye trauma. This finding may be from the researcher point of view due to the positive effect of the designed guidelines in improving the level of mothers' practices about ophthalmological eye trauma.

This finding was congruent with Jovanovic et al., (2021) who conducted a study entitled "The Risk and Protective Factors for Pediatric Eye Injuries: A CaseCrossover Study" and found that Giving the best model to predict injuries, the combined strategies of teaching, modifying the environment, and the watchful supervision present a preventive triad that needs to be further explored and encouraged in practice.

Regarding to correlation between total knowledge and total practices scores of studied mothers The study found that, there is a highly positive statistical correlation between mothers' total knowledge and their total practices scores pre and post guidelines. This might be due to knowledge play an important role in changing leading to change of practices. Also the increase in total knowledge was associated with an increase in the total practice score. This study agreed with Arishia et al., (2019) who conducted a study about "Childhood eye care services in south Darfur state of Sudan: Learner and parent perspectives" and found that there was highly statistical correlation between total knowledge and total practices.

\section{Conclusion}

The research hypothesis was accepted and the majority of studied mothers had adequate knowledge and satisfactory practice post implementation of designed guidelines as compared to pre designed guidelines with highly statistically significant improvement.

\section{Recommendations}

- The nursing roles should be directed toward educating mothers about proper care for children with ophthalmological trauma.

- Conducting periodical programs for nurses in Ophthalmology Department for continuous regular updating of their knowledge and practices regarding ophthalmological trauma.

- Follow up program for children with ophthalmological trauma should be organized and applied in the ophthalmological hospitals/ departments, for the proper application of proper management, prognosis of ophthalmological trauma on the children, relieving of the signs and symptoms and prevent complications.

- Further studies are recommended regarding implementation of educational programs about ophthalmological trauma in different health care settings.

\section{References}
Al Mazrou A., Alsobaie N., Abdulrahman A., and Al Obaidan O., (2020). Do Saudi parents have sufficient awareness of pediatric eye diseases in Riyadh?. Saudi journal of ophthalmology, 34(3): 171-176. 
Arishia S., Naidoo K., and Clarke-Farr P., (2019). Childhood eye care services in south Darfur state of Sudan: Learner and parent perspectives. Afr Vis Eye Health, 75(1): 1-13.

Baashar A.S., Halawani M.A., Alharbi W.I., Alhaz G.A., Alam S.S., Tirkistani M.F., and Nour Eldin E.M., (2020). Parents' knowledge and practices about child eye health care in Saudi Arabia. International Journal of Medicine in Developing Countries, 4(2):454-460.

Barry R., Sii F., Bruynseels A., Abbott J., Blanch R., MacEwen, C., and Shah P., (2019). The UK Paediatric Ocular Trauma Study 3 (POTS3): clinical features and initial management of injuries. Clinical Ophthalmology. 13(3): 1165-1172.

Carlsson A., Dykes A.K., Jansson A., and Bramhagen A., (2016). Mothers' awareness towards child injuries and injury prevention at home: a guidelines study. BMC Research Notes, 9(1): 1-6.

D'Antone V., Flórez D.P., García C., and Manrique F., (2021). Pediatric Ocular Trauma from A Tertiary Public Hospital in Colombia: Epidemiological Characterization. Research Square. 21(1):248.

Eldaly M., Abdel Hakim M., and Zaki R. (2013). Eye trauma during the 2011 Egyptian revolution. Graefe's Archive for Clinical and Experimental Ophthalmology, 251(3):661-5.

Guo Y., Liu Y., Xu H., Zhao Z., and Gan D., (2021). Characteristics of paediatric patients hospitalized for eye trauma in 20072015 and factors related to their visual outcomes. Eye, 35(3):945-951.

Hong Y., and Song W., (2018). Textbook of ophthalmology, 1st ed, chapter 4, General Guideline of Ophthalmic Emergency, Springer, Singapore.
Jovanovic N., Peek-Asa C., Zhang L., Cavanaugh J.E., Pidro A., and Alajbegovic-Halimic J., (2021). The Risk and Protective Factors for Pediatric Eye Injuries: A Case-Crossover Study, 28(6):479487.

Lippincott, (2018). Lippincott Nursing Procedures, $8^{\text {th }}$ ed, Eye Care, Wolters Kluwer Health, Philadelphia, 350-355.

Podbielski D.W., Surkont M., Tehrani N.N., and Ratnapalan R.S., (2016). Pediatric eye injuries in a Canadian emergency department. Canadian Journal of Ophthalmology, 44 (5):519-522.

Sukati V.N., Moodley V.R., and Mashige K.P., (2018). Knowledge and practices of parents about child eye health care in the public sector in Swaziland. African Journal of Primary Health Care \& Family Medicine, 10(1): 1808.

Tichauer M.B., (2021). Ocular Trauma: 8 Potentially Devastating Eye Injuries. Medscape, 4(2):454-460. 
تأثير الإرشادات التوجيهية المصممة للأمهات فيما يتعلق برعاية أطفالهن المصابين بإصابات العيون

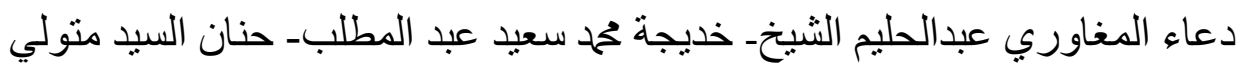

تعتبر إصابات العيون من الأسباب الرئيسية للإعاقة والإعتلال البصري الذي يؤثر بشكل خاص على

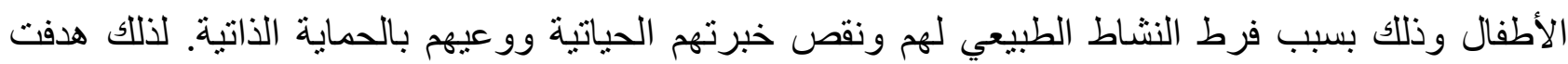

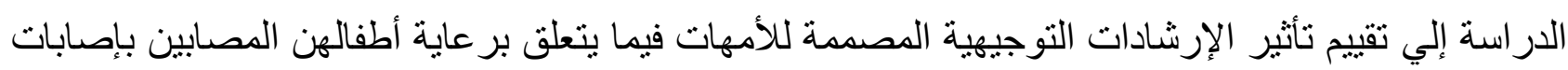

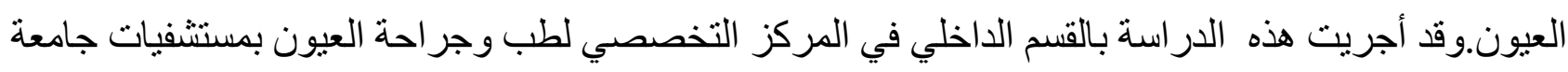

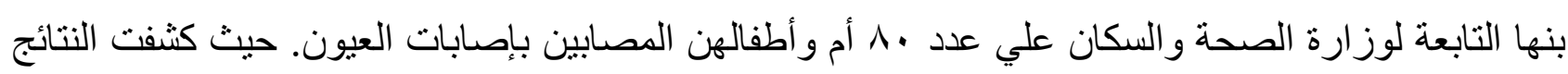

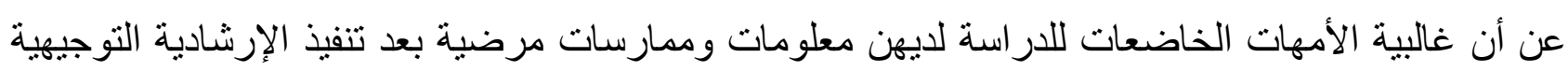

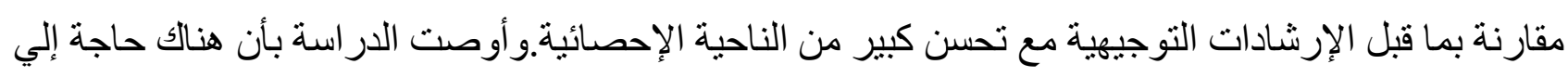

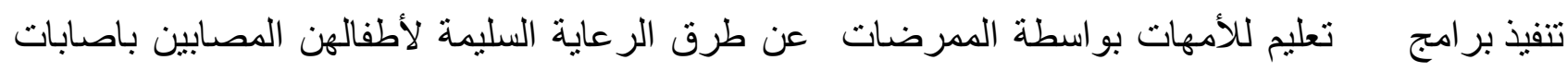

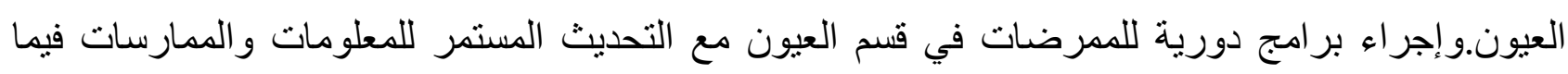

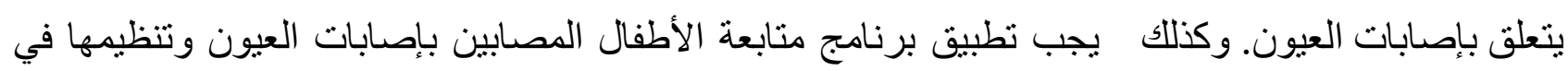

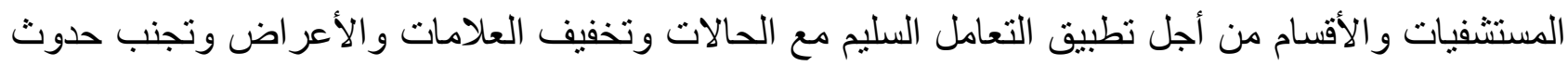
مضاعفات. كما يوصى بإجر اء مزيد من البرامج عن إصابات العين في أماكن الرعاية الصحية المختلفة. 